\title{
Money and Inflation in Iran: Evidence from P* Model
}

\author{
Yazdan Naghdi, *Ahmad Jafari Samimi, Nasibeh Kakoei \\ Firoozkooh Branch, Islamic Azad University, Firoozkooh, Iran \\ jafarisa@yahoo.com*
}

\begin{abstract}
This study with its monetary viewpoint and in the form of $\mathrm{P}^{*}$ model surveyed to test the money affect on inflation in Iranian economy. To achieve this goal OLS, ARDL techniques were used during 19792008. It should be noted that only the standard $\mathrm{P}^{*}$ model (domestic price gap) were tested in this study. Considering that domestic price gap consists of output gap and velocity gap, the Hedrick-Prescott filter method is used to estimate the potential production levels and the velocity. Estimation results of various models show that the standard $\mathrm{P}^{*}$ model (domestic price gap) is not able to explain and forecast inflation in Iran.
\end{abstract}

Key words: Inflation, money, $P^{*}$ model, output gap, Velocity gap, Hedrick- Prescott filter.

\section{Introduction}

Inflation is one of the most acute economic problems in various countries including Iran in recent decades. This phenomenon makes much malfunction on both economical, policy system that we can pointed at economical instability, poverty, decreasing of economical growth rate, and it is following decreasing of general welfare, increasing in inequality of income distribution, decreasing in long run investment. By attention to these effects, agreement is on which should be the long run goal monetary policy in price stability. However, the important point is that economist of different schools do not agree with each other about the causes of inflation creation. Based on some of economical ideas the source of inflation is money, this lookout that is related to monetarist's school, contemplates change in volume of money as the main effective cause on inflation, especially in long run, in the sense that steady and continuous growth of money volume can create high inflation. Based on this attitude central bank consider control of money volume as one of the main tools of monetary policy to control inflation. This research with its monetary attitude and in the form of $\mathrm{P}^{*}$ model survived the relationship between money and inflation in the Iran economy. The root of $\mathrm{P}^{*}$ model can be found in the quantity of money theory. In this model, there is a systematic relation between money and the levels of prices that based on we can study inflation status and forecast future process of prices which this topic has much important for monetary status and economical diplomats. This model can be tested in 2 states: I) $\mathrm{P}^{*}$ test at domestic price gap state (Standard $\mathrm{P}^{*}$ model) II) $\mathrm{P}^{*}$ test at foreign price gap state. That just $\mathrm{P}^{*}$ test at domestic price gap (Standard $\mathrm{P}^{*}$ model) is engaged in this research. Domestic price gap is a mix of output gap and velocity gap. Estimating of $\mathrm{P}^{*}$ model needs to primary which we can pointed to potentially output estimate, output gap, equilibrium velocity and velocity gap. There are money methods for estimating of these variables it is used of Hedrick - Prescott filter method for this goal in this research.

P* model stability makes that this model is used as an inflation model in different countries. The different results have been achieved of this studies, some instance are: there is a hard and long run relation between money and prices level and inflation is a monetary phenomenon in America (Hallman, Porter and Small 1991). Domestic price gap (based on instability of velocity) is unable to determine inflation in Iran and instead of this foreign price gap is able to determine inflation in this country (Azizi 2000). Money does not play an important and significance for inflation prediction in future and inflation is not monetary in Norway and united Europe (Eitrheim 2003). Money and output gap have a significant role in forecasting inflation in the Chile and Mexico (Sanchez-Funga 2007). In empirical studies section it is engaged to done studies in this field broadly. In this paper we study a causal relationship between inflation and money based on $\mathrm{P}^{*}$ model in Iran. In section 2 comes empirical studies in this field, in section 3 discussed about data and methodology, in section 4 comes results and in section 5 comes conclusion of the study.

Empirical Studies: Garcia and Pradhan (1998) used P* model for the analysis of prices in Spain for the period of 1970-96. The results showed that both domestic and foreign price gap have positive coefficients so the results emphasized the practicality of $\mathrm{p}^{*}$ model for prediction. Clostermann and Seitz (2002) use $\mathrm{P}^{*}$ 
model to analyze the real and price effects of German monetary policy during 1973-97. The results show that the real effects of monetary policy are temporary and in a long run are neutral. Belke and Polleit (2004) apply a simple P-Star model to explain the inflation process in Sweden for the period of 19802004. Finding show that money - when measured by P-star or, alternatively: the real money gap - plays an important role for explaining inflation in Sweden, so the model has been applied successfully for the prediction of inflation in Sweden. Anglingkusumo (2005) analyzes the relationship between money and inflation in Indonesia based on the P* model during 1981-2002. In this paper, the effect of excess narrow money $\left(\mathrm{M}_{1}\right)$ on inflation in Indonesia before, during, and after the Asian crisis is empirically examined. The results show that the two regime $\mathrm{P}^{*}$ model, in terms of excess $\mathrm{M}_{1}$, tracks the long run dynamics of inflation in Indonesia remarkably well. While, there is evidence of a co-breaking relationship between excess $M_{1}$ and consumer prices in Indonesia during the Asian crisis. Herwarts and Reimers (2006), they analyzed in this study long run relationship between money, price level and production of 110 economic data based on P* model for the period of 1960-99. The Results have shown that there is a correlation between inflation and money (especially for countries with high inflation); there for controlling money growth will be the most effective factor in stabilizing prices. Sanchez-Funga (2007), evaluated in a study the usefulness of the real economy, money and exchange rate indicators in forecasting inflation based on $\mathrm{P}^{*}$ model for the economy of Chile and Mexico. The data is monthly, so that for Chile the data of 1990.01 to 2001.06 and for Mexico the data of 1986.1 to 2001.06 have been used. The results were shown that in the economy of both money and output gap have a significant role in forecasting inflation while the exchange rate in Mexico has been merely successful in predicting inflation. Özdemir and Saygllı (2008), have used the $\mathrm{P}^{*}$ model for analyzing the monetary pressure and inflation in Turkey. Results of data estimation during 1997 to 2007 have shown that the money based on $\mathrm{P}^{*}$ model has a significant role in forecasting inflation in Turkey. Mujeri (2009) used of the P-Star Model for Measuring Inflationary Pressure in Bangladesh for the period of 1980-2007. The empirical results show that the price gap model followed by the output gap model and the velocity gap model performs better, So $\mathrm{P}^{*}$ model performance was relatively good for the economy of Bangladesh.

\section{Data and Methodology}

This article discuses about causal relationship between inflation and money based on $\mathrm{P}^{*}$ model during 1979-2008 in Iran. Considering that, inflation is one of the most basic economic problems during the economic life of each country, explaining and forecasting inflation for policy makers and economic authorities is vital. Many models are designed to forecast inflation in the economy. One of these models is which that is known as $\mathrm{P}^{*}$ model that at first time it is designed by using of quantity theory for inflation determining and prediction by American's Federal Reserve analysis's Hallman, Porter and Small (HPS 1989,1991). They paid attention to money role's importance on inflation by determinant factors of stasis prices. The main hypothesis of this model is that there is a long run stasis and by using of it we can forecast inflation. By the way, that we can predict it by using of the gap between stasis and real prices that inflation will increase or decrease or will stay unchangeable and this is when real prices would be less, more or stasis level. In all of standard models of inflation, output gap is the most main variables though in $\mathrm{P}^{*}$ model velocity gap come in model as independent variable. This gives especial future to $\mathrm{P}^{*}$ model by paying attention to financial innovations which are done since 1980s in the world and effect on velocity and distinguish this from the other models of inflation determination (among financial innovations is creating a kind of current account which incidence interest to it and use of credit cards instead of money). In the other hand because of $\mathrm{P}^{*}$ model's flexibility it stasis and accordance with economical different status of different countries. Withal the most important features of this model are that engages to inflation prediction and future process of prices in economical instability status in woods and money market. (The entire stated reasons make that it is used of $\mathrm{P}^{*}$ model in this research.)

The main idea of quantity theory of money is that there is a relationship between quantity from one side and price from the other side, In other words:

$\mathrm{P} . \mathrm{Y}=\mathrm{M} . \mathrm{V}$

$\mathrm{P}=\mathrm{M}(\mathrm{V} / \mathrm{Y})$

Which $\mathrm{M}$ is Volume of money, $\mathrm{V}$ is velocity of money, and $\mathrm{Y}$ is real output.

The above model shows the general level of prices behavior corresponding with money growth and thus, HPS defines the equilibrium price level as following:

$\mathrm{P}^{*}=\mathrm{M}\left(\mathrm{V}^{*} / \mathrm{Y}^{*}\right)$ 
Which, $\mathrm{Y}^{*}$ is the potential output level and $\mathrm{V}^{*}$ is the equilibrium velocity of money. We divide equation (3) on equation (2) and logarithm of it, we give:

$$
\begin{aligned}
& \mathrm{P}^{*} / \mathrm{P}=\left(\mathrm{V}^{*} / \mathrm{Y}^{*}\right) /(\mathrm{V} / \mathrm{Y}) \\
& \mathrm{P}^{*} / \mathrm{P}=\left(\mathrm{V}^{*} \mathrm{Y}\right) /\left(\mathrm{Y}^{*} \mathrm{~V}\right) \\
& \mathrm{P}^{*}-\mathrm{P}=\left(\mathrm{V}^{*}-\mathrm{V}\right)+(\mathrm{Y} \\
&\left.-\mathrm{Y}^{*}\right)
\end{aligned}
$$

According to equation (6) it is evident that the existence of the price gap indicates the existence of output gap and velocity gap. Since the price gap does not provide any information about the adjusting way in which $\mathrm{P}$ became $\mathrm{P}^{*}$, the hypothesis (7) is require.

$$
\mathrm{dp}-\mathrm{dp} \mathrm{p}_{-1}=\mathrm{a}\left(\mathrm{p}_{-1}{ }^{*}-\mathrm{p}_{-1}\right) \quad \mathrm{a}>0
$$

A indicates adjustment speed of current prices in to equilibrium price of $\mathrm{P}^{*}$. In the above equation for both parts of price gap means, velocity gap and output gap the same kind of coefficient restrictions are considered. Gaps can be placed separately in the equation:

$$
\begin{aligned}
\mathrm{dp}-\mathrm{dp}_{-1}=\mathrm{a}_{-1}\left(\mathrm{~V}_{-1}{ }^{*}-\mathrm{V}_{-1}\right)+\mathrm{a}_{2}\left(\mathrm{Y}_{-1}-\mathrm{Y}_{-1}{ }^{*}\right) & \mathrm{a}_{1}, \mathrm{a}_{2} \\
& >0
\end{aligned}
$$

To estimate inflation, the relation error correction terms between the actual price level and the potential price level has been used.

$$
\begin{gathered}
\mathrm{dp}=\mathrm{a}_{0}+\mathrm{a}_{1}\left(\mathrm{p}_{-1}^{*}-\mathrm{p}_{-1}\right)+\mathrm{a}_{3} \mathrm{dp_{-1 }}+\mathrm{a}_{4} \mathrm{dp_{-2 }} \\
+\mathrm{a}_{5} \mathrm{dp} \mathrm{p}_{-3} \\
\mathrm{dp}=\mathrm{a}_{0}+\mathrm{a}_{1}\left(\mathrm{~V}_{-1}{ }^{*}-\mathrm{V}_{-1}\right)+\mathrm{a}_{2}\left(\mathrm{Y}_{-1}-\mathrm{Y}_{-1}\right)+\mathrm{a}_{3} \mathrm{dp_{-1 }}+\mathrm{a}_{4} \mathrm{dp_{-2 }} \\
+\mathrm{a}_{5} \mathrm{dp_{-3 }}
\end{gathered}
$$

Inflation is the dependent variable. It means that the price gap will increase inflation. In the standard $\mathrm{P}^{*}$ model, it is assumed that $\mathrm{V}^{*}$ and $\mathrm{Y}^{*}$ are independent variable of money volume, so the price is a function of domestic money supply.

$$
\begin{aligned}
(\text { Gap })_{\mathrm{d}}= & \left(\mathrm{P}^{*}-\mathrm{P}\right) \\
& =\left(\mathrm{V}^{*}-\mathrm{V}\right)+\left(\mathrm{Y}-\mathrm{Y}^{*}\right)
\end{aligned}
$$

In which d (Gap) is the domestic price gap.

To consider the importance of currency system in determining inflation, the generalized $\mathrm{P}^{*}$ model has been used ${ }^{1}$.

\section{Results}

Standard P* model test by OLS: Due to high inflation in Iran in 1995, a dummy variable used to eliminate the effects of economic shocks of this year. In addition, to eliminate autocorrelation we have used AR process. Table (1) includes 3 estimated equations (Each line of table includes one equation) as follows:

In the first equation (first line) independent variable is output gap and in the second equation (second line) independent variable is velocity gap. Because $t$-statistic is not significant in both equations $(t<<2)$, so we can conclude that output gap and velocity gap don't effect on inflation in Iran's economy, in the other word, standard $\mathrm{P}^{*}$ model (domestic price gap) in which velocity and output gaps are independent variables can't explain inflation in Iran. For certainty on gained results, once sum of output and velocity gaps (means price gap) was pointed as independent variable in model (third line) and this time above results are confirmed based on inefficiency of $\mathrm{P}^{*}$ model in inflation determination and prediction for Iran's economy and consequently not being monetary of inflation in Iran's economy.

Figures in parentheses are t- statistic. Based on Gordon's triangle model the actual inflation rate is determined by the sum of: demand pull, cost push and built-in inflation, that built-in inflation is the main factor. In this regard in the studies by komayjani and Naghdi study (2008), komayjani and Naghdi (2009) and Loungani (2001) it is proven that the lag inflation (expected inflation) has a significant effect in 
justifying inflation in each period (in short run) in Iranian economy. The following test is done to verify this problem.

Table 1: Iran's standard $P *$ model tested by OLS (Inflation as dependent variable)

\begin{tabular}{rrrrrrrrr}
\hline $\mathbf{c}$ & GapGDP & GapV & GapGDP + GapV & D95 & AR(1) & R $^{2}$ & D.W & F \\
\hline 19.57 & -0.0002 & - & - & 20.59 & 0.60 & 0.59 & 1.55 & 12.002 \\
$(7.008)$ & $(-1.96)$ & & & $(3.97)$ & $(3.52)$ & & & \\
18.44 & - & 15.98 & - & 33.03 & - & 0.48 & 1.31 & 12.91 \\
$(15.61)$ & & $(1.74)$ & & $(5.01)$ & & & & \\
19.57 & & & -0.0002 & 20.59 & 0.60 & 0.59 & 1.55 & 12.002 \\
$(7.008)$ & - & - & $(-1.96)$ & $(3.97)$ & $(3.52)$ & & & \\
\hline
\end{tabular}

Table 2: The effect of lag inflation on inflation (Inflation as dependent variable P)

\begin{tabular}{rrrrrr}
\hline $\mathbf{c}$ & $\mathbf{P ( - 1 )}$ & $\mathbf{D 9 5}$ & $\mathbf{R}^{\mathbf{2}}$ & $\mathbf{D . W}$ & $\mathbf{F}$ \\
13.27 & 0.29 & 25.78 & 0.51 & 1.34 & 13.79 \\
$(4.48)$ & $(2.02)$ & $(3.82)$ & & & \\
\hline
\end{tabular}

Regarding to aforementioned table and by attention to t-statistic significance for lag inflation, the result of former researches based on effectiveness of lag inflation on inflation during (1979-2008) is confirmed too. So we can test $\mathrm{P}^{*}$ model by depending on lag inflation, too. The results of test are shown is table (3).

Table 3: Iran's standard $P^{*}$ model test based on OLS (Dependent variable of lag inflation)

\begin{tabular}{|c|c|c|c|c|c|c|c|}
\hline $\mathbf{c}$ & GapGDP & GapV & GapGDP + GapV & AR(1) & $\mathbf{R}^{2}$ & D.W & $\mathbf{F}$ \\
\hline $\begin{array}{r}19.94 \\
(6.88)\end{array}$ & $\begin{array}{r}-0.0001 \\
(-0.90)\end{array}$ & & 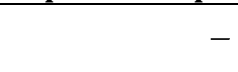 & $\begin{array}{r}0.49 \\
(2.92)\end{array}$ & 0.27 & 1.67 & 4.69 \\
\hline $\begin{array}{r}19.90 \\
(6.84)\end{array}$ & - & $\begin{array}{r}-0.30 \\
(-0.02)\end{array}$ & - & $\begin{array}{r}0.49 \\
(2.87)\end{array}$ & 0.24 & 1.57 & 4.14 \\
\hline $\begin{array}{r}19.94 \\
(6.88)\end{array}$ & - & - & $\begin{array}{r}-0.0001 \\
(-0.90)\end{array}$ & $\begin{array}{r}0.49 \\
(2.92)\end{array}$ & 0.27 & 1.67 & 4.69 \\
\hline
\end{tabular}

Table (3) includes three 3 estimated equations (Each line of table includes one equation) so: At the first, second and third equation, independent variable is output gap, velocity gap and price gap respectively. Results show that the coefficients of output gap, velocity gap and price gap variables have not any significance difference from zero statistically and t-statistic of all of above variables are not significant, too. So we can express further that standard $\mathrm{P}^{*}$ model, which is domestic price gap model really, is not enable to prediction and explanation of inflation in Iran's economy.

Despite that obtained resulted in standard $\mathrm{P}^{*}$ model test in status which dependent variable is inflation, are more significant than when dependent variable is lag inflation (because of existence of coefficient of determination), but in sum, standard $\mathrm{P}^{*}$ model (domestic price gap) isn't a suitable model for inflation explanation in Iran's economy based on OLS method. By pat attention to this that this model enroots in quantity theory, we can say that quantity theory is not comported in Iran's economy meaning inflation isn't monetary in Iran's economy. We consider standard P* model based on ARDL method now.

Standard $P^{*}$ model test based on ARDL method

Table 4: the results of Iran's standard $P *$ model tested by ARDL (Inflation dependent variable P)

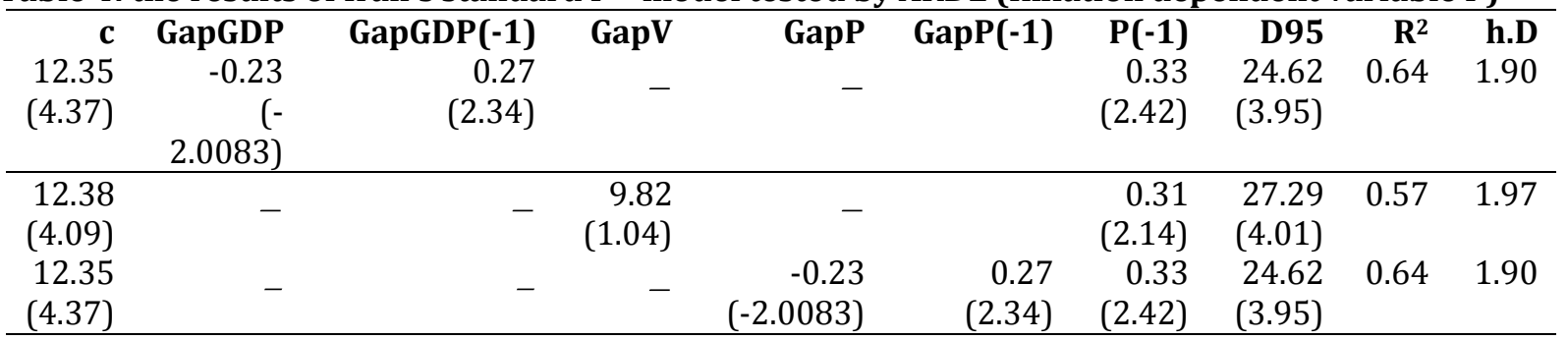


T-Statistic for doing test of long run relation among inflation and output gap $=-4.48$

$\mathrm{T}$-Statistic for doing test of long run relation among inflation and velocity gap $=-4.72$

T-Statistic for doing test of long run relation among inflation and price gap $=-4.48$

The result of short run estimation shows that there isn't a significance relation between inflation and velocity gap (Because of $\|\mathrm{t}\|<2$ for velocity gap). However, there is a significance and negative relation between output and price gaps with inflation. As the coefficient lag of price gap must be significance for predicting inflation by $\mathrm{P}^{*}$ model, and from table (4) one can observe a significance result. Therefore, we can state that inflation will increase in future, and the standard $\mathrm{P}^{*}$ model is a suitable for predicting inflation in Iran by ARDL method and in short run.

Table 5: The results of long run relation of Iran's standard P* model test (Inflation dependent variable P)

\begin{tabular}{|c|c|c|c|c|c|c|}
\hline & c & GapGDP & GapV & GapP & D95 & \\
\hline & $\begin{array}{r}18.50 \\
(10.94)\end{array}$ & $\begin{array}{r}0.66 \\
(0.45)\end{array}$ & - & - & & $\begin{array}{r}36.87 \\
(3.82)\end{array}$ \\
\hline $\begin{array}{l}18.01 \\
(10.25)\end{array}$ & & - & & - & $\begin{array}{l}39.69 \\
(3.81)\end{array}$ & \\
\hline & $\begin{array}{r}18.50 \\
(10.94) \\
\end{array}$ & - & - & $\begin{array}{r}0.66 \\
(0.45) \\
\end{array}$ & & $\begin{array}{r}36.87 \\
(3.82) \\
\end{array}$ \\
\hline
\end{tabular}

Regarding to the results of long run and by attention to being non-significant of t-statistic in all 3 equation, we can express that Standard P* model by ARDL method doesn't have necessary efficiency for inflation explanation and prediction of prices in future process in Iran's economy and the results of standard P* model test is confirmed by OLS method.

Table 6: the results of Iran's standard $P$ * model tested by OLS and ARDL

Method

Inflation dependent variable: the standard $\mathrm{P}^{*}$ model can't indicate inflation in Iran, meaning quantity theory isn't efficient in Iran's economy.

OLS

Dependent variable of lag inflation: the standard $\mathrm{P}^{*}$ model can't prediction and explanation of inflation in Iran's economy.

Short run: given the significant coefficient lag of price gap, we can express that standard $\mathrm{P}^{*}$ model is enabling to forecast inflation in Iran's economy.

ARDL

Long run: the standard $\mathrm{P}^{*}$ model is not ability to explanation inflation in Iran's economy.

Due to mismatch short run and long run results, the standard $\mathrm{P}^{*}$ model based on ARDL isn't efficient for inflation explanation and prediction of prices future process in Iran's economy.

Altogether and based on the results of OLS and ARDL can be concluded that the standard $\mathrm{P}^{*}$ model isn't efficient in Iran's economy and inflation isn't monetary in Iran's economy.

\section{Conclusion}

This study with its monetary viewpoint and in the form of $\mathrm{P}^{*}$ model surveyed to test the money affect on inflation in Iranian economy. To achieve this goal OLS, ARDL techniques were used during 1979-2008. It should be noted that only the standard P* model (domestic price gap) were tested in this study. Considering that domestic price gap consists of output gap and velocity gap, the Hedrick-Prescott filter method is used to estimate the potential production levels and the velocity. Estimation results of various models show that the standard $\mathrm{P}^{*}$ model (domestic price gap) is not able to explain and forecast inflation in Iran. 


\section{References}

Azizi, F. (2000). A projection of inflation gap on basis of $\mathrm{P}^{*}$ model in Iran. Journal of economic essays 2004, 1(2), 9-36.

Anglingkusumo, R. (2005). Money-Inflation Nexus in Indonesia: Evidence from a P-Star Analysis. Tinbergen Institute Discussion Paper, 05-054/4.

Belke, A. \& Polleit, T. (2004). A Model for Forecasting Swedish Inflation. Economics. Soc. uoc. gr/macro/ 9conf/docs/Sweden. November 2004.

Central Bank of the Islamic republic of Iran, central Bank's sheet, several years.

Clostermann, J. \& Seitz, F. (2002). Money, Inflation and Growth in Germany; a Vector- Error- Correction-PStar Model. Journal of Economics and Statistics, 222(6), 641-655.

Eitrheim, $\varnothing$. (2003). Testing the role of money in the inflation process. Advance Browser: www.eea.esem.com. February 2003.

Gordon, R. J. (1990). The Phillips curve now and then. Working paper, 3393.

Herwartz, H. \& Reimers, H. E. (2006). Long-Run Links among Money, Prices and Output: Worldwide Evidence. German Economic Review, 7, 65-86.

Hedric, R. J. \& Perscott, E. C. (1997). Postwar U.S. business Cycles: An Empirical Investigation. Journal of Money, Credit and Banking, 29, 1-16.

Hallman J. J., Porter, R. \& Small,H. D. (1991). Is the Price Level Tied to the M2 Monetary Aggregate in the Long Run?. The American Economic Review, 841-858

Khashaverdian, E. (1999). The study of existence of stationary in time series statistic of country's economy. Monetary and Bank research institution of Iran

Komijani, A. \& Naghdi, Y. (2008). The study of production effects agriculture and services on inflation in Iran's economy. Researches and economical polices magazine, 45, 59-86.

Komijani, A. \& Naghdi, Y. (2009). The study of the adverse relation among output and inflation in Iran's economy (By emphasizing on output size). Economy sciences researches, ninth year,1 (successive 32), 99-124.

Loungani, P. \& Swagel, P. (2001). Sources of Inflation in Developing Countries. IMF Working Paper, December 2001.

Manoj, V. \& Pradhan, A. G. (1998), The domestic and foreign price gaps in the P-Star Model: Evidence from Spain. IMF Working Paper, 64.

Mujeri, M., hahiduzzaman, V. \& Ezazul, I. (2009). Application of the P-Star Model for Measuring Inflationary Pressure in Bangladesh. The Bangladesh Development Studies, XXXII, 1, March 2009.

Nofresti, M. (1999). The unit root and cointegration in economize. Rasa cultural service institution, first edition. In Persian.

Özdemir, K. A. \& Saygl, M. (2008). Monetary Pressures and Inflation Dynamics in Turkey: Evidence from P-Star Model. Research and Monetary Policy Department Working Paper, 08/08.

Sánchez-Fung, J. R. (2007). Inflation Targeting and Monetary Analysis in Chile and Mexico. Quantitative and Qualitative Analysis in Social Sciences, 3, 40-62. 